\title{
The effectiveness of tofacitinib, a novel Janus kinase inhibitor, in the treatment of rheumatoid arthritis: a systematic review and meta-analysis
}

\author{
Pawel Kawalec • Alicja Mikrut • Natalia Wiśniewska • \\ Andrzej Pilc \\ Received: 17 June 2013 / Accepted: 26 June 2013 / Published online: 23 July 2013 \\ (C) The Author(s) 2013. This article is published with open access at Springerlink.com
}

\begin{abstract}
The aim of the present study was to conduct a meta-analysis of the effectiveness of tofacitinib, a novel oral Janus kinase inhibitor, recently approved for the treatment of active rheumatoid arthritis in patients who have failed previous treatment with methotrexate (MTX) or other diseasemodifying antirheumatic drugs (DMARDs). A systematic literature search was conducted in PubMed, EMBASE, Cochrane Library, and other databases till 3 May 2013. All included studies were analyzed with the use of the Review Manager 5.1.0. software according to the Preferred Reporting Items for Systematic Reviews and MetaAnalyses (PRISMA) Statement protocol. Nine randomized controlled trials (RCTs) comparing tofacitinib with placebo were identified. Two of them additionally provided the comparison with adalimumab. However, only eight RCTs met the inclusion criteria for the meta-analysis. The overall results of the meta-analysis showed that tofacitinib provided a statistically significant improvement according to the response criteria (ACR20/50/70) after 12 weeks of treatment when compared to placebo $(p<0.00001)$. Moreover, it was demonstrated that tofacitinib was significantly superior to adalimumab in achieving the ACR50 response criteria at week $12(p=0.003)$. For the safety analysis, there were no statistically significant differences between tofacitinib-, adalimumab-, and placebo-treated patients in respect to the
\end{abstract}

P. Kawalec $(\bowtie) \cdot$ A. Pilc

Drug Management Department, Institute of Public Health, Faculty of Health Sciences, Jagiellonian University, 20 Grzegorzecka St., 31-531 Kraków, Poland

e-mail: pawel.kawalec@uj.edu.pl

P. Kawalec $\cdot$ A. Mikrut $\cdot$ N. Wiśniewska

Centrum HTA Sp. z o.o. Sp. k, Kraków, Poland

A. Pilc

Department of Neurobiology, Institute of Pharmacology, Polish Academy of Sciences, Kraków, Poland risk of serious adverse events or treatment discontinuation due to adverse reactions $(p>0.05)$. The findings of this systematic review with meta-analysis indicate that tofacitinib monotherapy or with background methotrexate provides early statistically significant and clinically important improvement in rheumatoid arthritis symptoms and has an acceptable safety profile comparable to that of placebo. The results of the present meta-analysis show that the frequency of serious adverse events was not increased after tofacitinib treatment. In addition, tofacitinib might provide an effective treatment option compared to intravenous or subcutaneous biological DMARDs, as suggested by the result of the comparison made regarding tofacitinib vs. adalimumab ACR50 response rate.

Keywords Meta-analysis · Rheumatoid arthritis · Systematic review $\cdot$ Tofacitinib

\section{Introduction}

Rheumatoid arthritis (RA) is a chronic autoimmune disease characterized by systemic, destructive, and progressive inflammatory polyarthritis, driven by immune system dysregulation. RA affects approximately $1 \%$ of the world population and, if inadequately treated, leads to pain, swelling, and progressive destruction of joints, with resulting disability, substantial loss of functioning, and mobility or work incapacity, decrease in quality of life, or reduction of life expectancy [1-3]. Traditional disease-modifying antirheumatic drugs (DMARDs) have become the cornerstone of treatment for RA, with methotrexate (MTX) being most commonly used in clinical practice as monotherapy or in combination with other drugs [2, 3]. However, patients with an inadequate response to the treatment with conventional DMARDs or MTX might be treated with biological response modifiers targeting tumor necrosis factor (TNF) and 
interleukins (IL-6, IL-1), which play a pivotal role during the pathological processes active in RA and with biological agents targeting $\mathrm{T}$ and $\mathrm{B}$ cells $[3,4]$. Biological DMARDs (e.g., TNF inhibitors, abatacept, rituximab) are more efficacious than traditional DMARDs (e.g., methotrexate, sulfasalazine) in controlling joint damage and significantly improve physical function and quality of life [5]. Moreover, the combination of conventional and biological DMARDs may provide a faster resolution of the inflammatory process and may increase the response rate [4]. Although the introduction of biological agents with different immunological targets into clinical routine has been associated with a significant progress in RA treatment, a substantial proportion of patients do not achieve appropriate disease control and some of them discontinue therapy due to acquired therapeutic resistance or adverse events [3]. For this reason, the search for new molecules with a better risk-to-benefit ratio is ongoing and, furthermore, inhibitors of signal transduction via the intracellular pathways of inflammation are now in development. The cytokines involved in immune regulation play crucial roles in the pathogenesis of RA, and members of the Janus kinase (JAK) family are essential for such signal transduction. Tofacitinib is a novel selective inhibitor of JAKs investigated as a targeted immunomodulator and a disease-modifying therapy for RA [5]. Tofacitinib has already been approved by the FDA for adult patients with moderately to severely active RA who have had an inadequate response or intolerance to methotrexate [6]. It might be used as monotherapy or in combination with methotrexate or other synthetic DMARDs. The drug is currently under regulatory review in Europe and Japan [3].

The aim of this systematic review with meta-analysis was to evaluate the efficacy and safety of tofacitinib orally administered to patients with active RA in whom MTX or other DMARDs produced an inadequate response or intolerance.

\section{Materials and methods}

This systematic review was performed according to the methods and recommendations from the Cochrane handbook [7], and the meta-analysis was performed according to the Preferred Reporting Items for Systematic Reviews and Metaanalyses (PRISMA) Statement protocol, as described elsewhere [8].

\section{Eligibility criteria}

Randomized controlled trials (RCTs) or abstracts published in peer-reviewed journals, evaluating the use of tofacitinib vs. placebo or adalimumab for the treatment of adult ( $\geq 18$ years of age) patients diagnosed with active RA in whom MTX,
DMARDs, or TNF inhibitors caused an inadequate response or intolerance, were included in the analysis.

\section{Data sources}

Primary studies were identified by searching the electronic databases (PubMed, EMBASE, Cochrane Central Register of Controlled Trials) and register of clinical trials (www. clinicaltrials.gov) for unpublished or ongoing trials and by scanning the lists of references from the identified studies or review articles. The websites of the European League Against Rheumatism and American College of Rheumatology were additionally searched for relevant information concerning the clinical trials. Cochrane Database of Systematic Reviews, DARE, PubMed, and EMBASE databases were also searched for review articles. The search was conducted till 3 May 2013.

\section{Search strategy}

Searches for primary studies were restricted and based on appropriate MeSH and EMTREE terms that met the requirement: rheumatoid arthritis and the intervention - tofacitinib, combined with Boole's logical operators (Table 1). The applied limits included human subjects and English, French, and German languages. The full-text articles were preferred because of opportunity to verify the reliability of potentially useful studies, but due to the lack of certain results in the fulltext papers, we extracted the necessary data from the register of controlled trial.

Study selection

The search and eligibility assessments were performed independently by two reviewers (A.M., N.W.). Disagreements were resolved by consensus, and when needed, a third reviewer acted as an adjudicator (P.K.). All titles were screened, potential abstracts were read, and possible articles were retained and their full text was critically reviewed. Studies fulfilling the eligibility criteria were included in the meta-analysis.

Data collection process

Data were extracted from the included studies by a single reviewer using a standard data extraction form, and then, they were checked by a second reviewer. Essential information from each trial was collected: study design, characteristics of participants, intervention and dosing regimen, concomitant therapy, duration of treatment, and clinical outcomes. All studies were also scored by two independent reviewers in accordance to the Jadad scale [9]. 
Table 1 MeSH subject headings and EMTREE keywords used in constructed search strategy for primary studies (last updated 3 May 2013)

Keywords (combined with Boole's logical operator, OR)

Medical condition: rheumatoid arthritis; rheumatic arthritis; chronic polyarthritis; rheumarthritis; rheumatism

Intervention: $\quad$ tofacitinib; tasocitinib; xeljanz; CP 690,550; CP690550; CP-690550; CP 690550; CP-690,550; cp690550-10; cp690550 10

Methodological PubMed: Humans, Randomized Controlled Trial, Clinical Trial, Controlled Clinical Trial; EMBASE: Humans, Controlled

limits: $\quad$ Clinical Trials, Randomized Controlled Trial, Embase only; Cochrane Central Register of Controlled Trials: No limits

applied; word variations have been searched

Language limits: $\quad$ PubMed, EMBASE: English, French, German

\section{Outcomes}

The response rate to treatment with tofacitinib assessed according to the American College of Rheumatology (ACR) criteria [10] was the primary measure of outcomes. These definitions included different variables, such as tender and swollen joint counts, patient's assessment of global pain, physician's assessment of disease activity, Health Assessment Questionnaire (HAQ), and laboratory parameters (either the C-reactive protein level or the erythrocyte sedimentation rate). We also evaluated status of patients' physical function with the use of the Health Assessment Questionnaire-Disability Index (HAQ-DI). Safety was evaluated based on the proportion of patients who experienced serious adverse events (SAEs) or discontinued the treatment due to adverse events.

\section{Statistical analysis}

Efficacy and safety were analyzed using dichotomous data. The beneficial impact of the intervention was expressed as the relative benefit ( $\mathrm{RB}$, described as the risk ratio or relative risk [RR] presented in the graphs due to specific labeling of the measurement of the effect in the statistical analysis software) with $95 \%$ confidence intervals (CIs). Adverse events were summarized with RR. The results obtained from separate trials were combined using appropriate methods of meta-analysis. The inverse variance in Mantel-Haenszel or DerSimonian-Laird effects model was used according to the data input and heterogeneity of test results. The results for sufficiently similar outcomes and homogenous data (determined by the degree of clinical and statistical heterogeneity) were pooled. The clinical heterogeneity was assessed by examining the characteristics of the featured studies, whereas the statistical heterogeneity was assessed using the chisquare test, with the significance set at $p=0.10$. Relative parameters were calculated using the fixed effects model when the statistical heterogeneity was not detected, and the random effects model was used when heterogeneity was present $(p<0.10)$. All statistical tests and creations of forest plots were carried out using the Review Manager version 5.1.0. software.

\section{Results}

Selection process and quality and characteristics of the included studies

Of the 65 articles retrieved after the initial search, 15 selected studies were reevaluated on the basis of full text and six were not eligible. Also, one additional study was identified after the search of lists of references in review articles, and finally, ten references describing nine RCTs fulfilled the inclusion criteria [11-20] but only eight RCTs met the inclusion criteria for the meta-analysis [11-17, 20] (Fig. 1).

The characteristics of the included studies are described in Table 2. All of them were randomized, double-blind, placebo-controlled, and multicentre trials. Eight RCTs were described in nine full-text papers published in peer-reviewed journals [11-19]. One study [20] was available only in abstract form, but the data were included in the metaanalysis though as a lower grade evidence. A majority of the randomized studies scored $\geq 3$ points on the Jadad scale, indicating a moderate or high methodological quality. Only phase III trials had clearly described methods of randomization [13-16]. All phase II trials scored three points due to a lack of description of randomization and blinding methods. No published articles mentioned an allocation concealment in the studies. The quality of one RCT [20] could not be accurately estimated due to a lack of the full-text version; however, the study was double-blinded.

Patients in all included studies had active RA diagnosed on the basis of the ACR 1987 revised criteria [21], with an inadequate response to previous MTX monotherapy [11-13, 15], anti-TNF agents [14], or generally nonbiological/ biological DMARDs [16-20] or to discontinued therapy due to unacceptable toxicity from these drugs. All of the included studies compared tofacitinib with placebo, and additionally, two trials provided the comparison with adalimumab. In phase II studies, multiple dosages of tofacitinib (1, 3, 5, 10, $15 \mathrm{mg}$ 


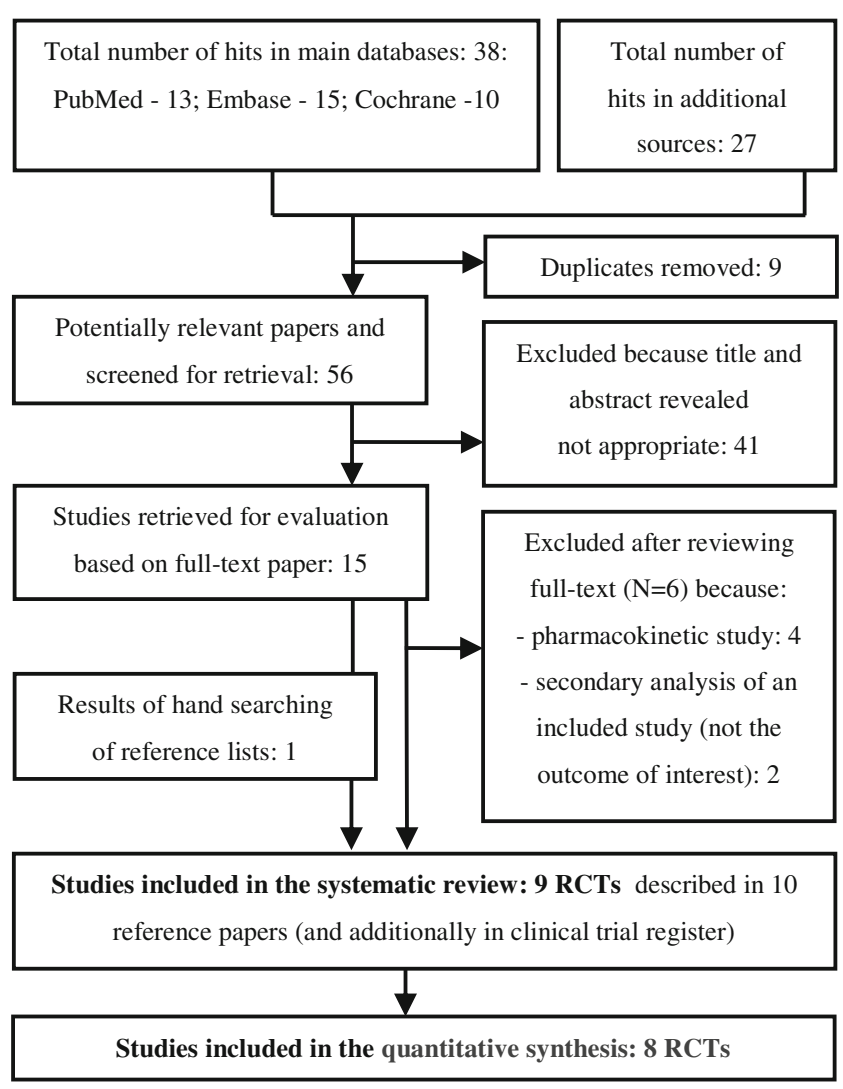

Fig. 1 PRISMA flow diagram for identification and selection of studies included in the systematic review and meta-analysis

twice a day) were assessed, but in phase III trials, doses of 5 and $10 \mathrm{mg}$ twice a day (bid) were selected as optimal for evaluation. In the eligible studies, tofacitinib was used concomitantly with stable doses of an MTX background [11-15] or was given as monotherapy [16-20]; however, drugs other than DMARDs were generally permitted in both subgroups (e.g., acetaminophen, nonsteroidal anti-inflammatory drugs, corticosteroids). Duration of treatment ranged from 6 to 48 weeks.

\section{Meta-analysis}

We performed the meta-analysis of eligible RCTs that compared tofacitinib with placebo or adalimumab. For comparisons, we extracted data where tofacitinib was used at the recommended dose for the commercially marketed product (5 $\mathrm{mg}$ twice a day) based on FDA approval [6]. The response rates based on the ACR criteria (ACR20/50/70) were the efficacy endpoints. An ACR20 response was defined as at least $20 \%$ improvement in both the tender joint count and the swollen joint count and at least $20 \%$ improvement in three of five other core set measures: patient's assessment of pain, patient's global assessment of disease activity, physician's global assessment of disease activity, patient's assessment of physical function, or acute-phase reactant value. For ACR50 and ACR70, patients had 50 and $70 \%$ improvement, respectively, according to the above-mentioned criteria [10]. An additional efficacy endpoint, i.e., physical function status measured by the HAQ disability index, was reported in the studies as the mean change from baseline in the HAQ-DI score or the percentage of patients who had reductions in the score of at least 0.22 or 0.30 points, indicating improvement of physical function. Finally, we evaluated only the dichotomous data because of their greater availability within the publications. For safety assessment, we analyzed the incidence of SAEs and the risk of treatment discontinuation due to adverse events. The analyses were performed in two subgroups: for studies assessing tofacitinib used in combination with MTX background and for studies on tofacitinib used as monotherapy. The data for efficacy and safety evaluation were extracted at week 12. Therefore, the results of the studies $[18,19]$ lasting only for 6 weeks of treatment could not be included in the meta-analysis.

A meta-analysis of the efficacy of tofacitinib vs. placebo

\section{$A C R$ response rate}

All eight eligible RCTs evaluated the clinical response to treatment according to the ACR criteria; five studies [11-15] dealt with the efficacy of tofacitinib in comparison with placebo, both given concomitantly with stable doses of MTX and three studies [16, 17, 20] compared tofacitinib with placebo without the background of MTX or other DMARDs. The overall result of the meta-analysis demonstrated that tofacitinib was significantly superior to placebo in achieving the ACR20 improvement criteria after 12 weeks of treatment $\left(\mathrm{RB}_{\text {random }}, 0.43 ; 95 \% \mathrm{CI}\right.$, 0.34 to $0.55 ; p<0.00001)$. ACR20 responses are presented in Fig. 2. ACR50 responses within 12 weeks of treatment with tofacitinib compared to placebo showed that the relative benefit $\left(\mathrm{RB}_{\text {fixed }}\right)$ was $0.29(95 \% \mathrm{CI}, 0.23$ to $0.37 ; p<0.00001)$. A total of $30 \%$ of the tofacitinibtreated patients achieved an ACR50 response compared to $10 \%$ of patients receiving placebo, irrespective of backbone therapy. The $\mathrm{RB}_{\text {fixed }}$ of achieving ACR70 was 0.19 (95\% CI, 0.12 to $0.29 ; p<0.00001)$ and $15.3 \%$ of patients receiving tofacitinib vs. $2.1 \%$ of the control group achieved this ACR response, indicating an absolute benefit of $13.2 \%$.

Results of the analysis in subgroups showed that the probability of ACR20/50/70 response to treatment was significantly higher for both tofacitinib in combination with MTX and tofacitinib monotherapy when compared to placebo. 
Table 2 Characteristics of the included studies

\begin{tabular}{|c|c|c|c|}
\hline $\begin{array}{l}\text { Author and year of } \\
\text { publication [ref.], } \\
\text { design }\end{array}$ & Population & $\begin{array}{l}\text { Dosage and schedule, and duration of treatment and } \\
\text { follow-up }\end{array}$ & No. of patients (for efficacy) \\
\hline $\begin{array}{l}\text { Tanaka } 2011[11] \\
\text { RCT phase II }\end{array}$ & $\begin{array}{l}\text { Active RA with an inadequate } \\
\text { response to MTX alone } \\
\text { (Japanese patients only) }\end{array}$ & $\begin{array}{l}\text { Tofacitinib } 1,3,5 \text {, or } 10 \mathrm{mg} \text { bid or placebo; stable } \\
\text { background MTX; } 12 \text { weeks }\end{array}$ & $\begin{array}{l}\text { Tofacitinib } 5 \mathrm{mg} \text { bid, } \\
\quad N=27 ; \text { placebo, } N=28\end{array}$ \\
\hline $\begin{array}{l}\text { Kremer } 2012 \text { [12], } \\
\text { RCT phase II }\end{array}$ & $\begin{array}{l}\text { Active RA with an inadequate } \\
\text { response to MTX alone }\end{array}$ & $\begin{array}{l}\text { Tofacitinib } 1,3,5,10 \text {, or } 15 \mathrm{mg} \text { bid or } 20 \mathrm{mg} / \text { daily or } \\
\text { placebo; stable background MTX; } 24 \text { weeks (after week } \\
\text { 12, nonresponder placebo [as well as tofacitinib } 1 \text { or } 3 \mathrm{mg} \\
\text { bid and } 20 \mathrm{mg} \text { /daily]-treated patients were advanced to } \\
\text { tofacitinib) }\end{array}$ & $\begin{array}{l}\text { Tofacitinib } 5 \mathrm{mg} \text { bid, } \\
\quad N=71 ; \text { placebo, } N=69\end{array}$ \\
\hline $\begin{array}{l}\text { van Vollenhoven } \\
2012 \text { [13], RCT } \\
\text { phase III }\end{array}$ & $\begin{array}{l}\text { Active RA with an inadequate } \\
\text { response to MTX alone }\end{array}$ & $\begin{array}{l}\text { Tofacitinib } 5 \text { or } 10 \mathrm{mg} \text { bid or placebo or adalimumab } 40 \mathrm{mg} \\
\text { once every } 2 \text { weeks; stable background MTX; } 48 \text { weeks } \\
\text { (after week } 12 \text {, nonresponder placebo-treated patients } \\
\text { were advanced to tofacitinib) }\end{array}$ & $\begin{array}{l}\text { Tofacitinib } 5 \mathrm{mg} \text { bid, } \\
\quad N=204 ; \text { placebo, } N=108 \text {; } \\
\text { adalimumab, } N=204\end{array}$ \\
\hline $\begin{array}{l}\text { Burmester } 2013 \text { [14], } \\
\text { RCT phase III }\end{array}$ & $\begin{array}{l}\text { Active RA with an inadequate } \\
\text { response or intolerance to } \\
\text { TNFi and MTX }\end{array}$ & $\begin{array}{l}\text { Tofacitinib } 5 \text { or } 10 \mathrm{mg} \text { bid or placebo; stable background } \\
\text { MTX; } 24 \text { weeks (after week 12, placebo-treated patients } \\
\text { were advanced to tofacitinib) }\end{array}$ & $\begin{array}{l}\text { Tofacitinib } 5 \text { mg bid, } \\
\qquad N=133 ; \text { placebo, } N=132\end{array}$ \\
\hline $\begin{array}{l}\text { van der Heijde } 2013 \\
\text { [15], RCT phase } \\
\text { III }\end{array}$ & $\begin{array}{l}\text { Active RA with an inadequate } \\
\text { response to MTX }\end{array}$ & $\begin{array}{l}\text { Tofacitinib } 5 \text { or } 10 \mathrm{mg} \text { bid or placebo; stable background } \\
\text { MTX; } 48 \text { weeks (after week 12, nonresponder placebo- } \\
\text { treated patients were advanced to tofacitinib) }\end{array}$ & $\begin{array}{l}\text { Tofacitinib } 5 \text { mg bid, } \\
\qquad N=321 ; \text { placebo, } N=160\end{array}$ \\
\hline $\begin{array}{l}\text { Fleischmann } 2012 \\
\text { [16], RCT phase } \\
\text { III }\end{array}$ & $\begin{array}{l}\text { Active RA with an inadequate } \\
\text { response or intolerance to } \\
\text { DMARDs }\end{array}$ & $\begin{array}{l}\text { Tofacitinib } 5 \text { or } 10 \mathrm{mg} \text { bid or placebo; monotherapy; } \\
24 \text { weeks (after week 12, placebo-treated patients were } \\
\text { advanced to tofacitinib) }\end{array}$ & $\begin{array}{l}\text { Tofacitinib } 5 \mathrm{mg} \text { bid, } \\
\quad N=243 ; \text { placebo, } N=122\end{array}$ \\
\hline $\begin{array}{l}\text { Fleischmann } 2012 \\
\text { [17], RCT phase II }\end{array}$ & $\begin{array}{l}\text { Active RA with an inadequate } \\
\text { response or intolerance to } \\
\text { DMARDs }\end{array}$ & $\begin{array}{l}\text { Tofacitinib } 1,3,5,10 \text {, or } 15 \mathrm{mg} \text { bid or placebo or } \\
\text { adalimumab } 40 \mathrm{mg} \text { once every } 2 \text { weeks; monotherapy; } \\
24 \text { weeks (after week } 12 \text {, nonresponder placebo [as well } \\
\text { as tofacitinib } 1 \text { or } 3 \mathrm{mg} \text { bid]-treated patients were } \\
\text { advanced to tofacitinib) }\end{array}$ & $\begin{array}{l}\text { Tofacitinib } 5 \mathrm{mg} \text { bid, } \\
\quad N=49 ; \text { placebo, } N=59 ; \\
\text { adalimumab, } N=53\end{array}$ \\
\hline $\begin{array}{l}\text { Kremer } 2009 \text { [18], } \\
\text { Coombs } 2010 \\
\text { [19], RCT phase II }\end{array}$ & $\begin{array}{l}\text { Active RA with an inadequate } \\
\text { response or intolerance to } \\
\text { DMARDs }\end{array}$ & $\begin{array}{l}\text { Tofacitinib 5, } 15 \text {, or } 30 \mathrm{mg} \text { bid or placebo; monotherapy; } \\
6 \text { weeks (followed up for an additional } 6 \text { weeks) }\end{array}$ & $\begin{array}{l}\text { Tofacitinib } 5 \mathrm{mg} \text { bid, } \\
\quad N=61 ; \text { placebo, } N=65\end{array}$ \\
\hline $\begin{array}{l}\text { Tanaka } 2011 \text { (abs) } \\
\text { [20], RCT phase II }\end{array}$ & $\begin{array}{l}\text { Active RA with an inadequate } \\
\text { response to DMARDs }\end{array}$ & $\begin{array}{l}\text { Tofacitinib } 1,3,5,10,15 \mathrm{mg} \text { or placebo; monotherapy; } \\
12 \text { weeks }\end{array}$ & $\begin{array}{l}\text { Tofacitinib } 5 \mathrm{mg} \text { bid, } \\
\quad N=50 ; \text { placebo, } N=48\end{array}$ \\
\hline
\end{tabular}

bid twice daily, DMARDs disease-modifying antirheumatic drugs, MTX methotrexate, $R C T$ randomized controlled trial, $T N F i$ tumor necrosis factor inhibitors

\section{$H A Q-D I$}

The rate of clinically significant improvement estimated by HAQ-DI response was based on the results from two studies $[11,14]$ assessing tofacitinib combined with MTX and from two studies $[16,17]$ concerning monotherapy. The overall result of meta-analysis showed that tofacitinib provided a statistically significant benefit compared to placebo in regard to improvement of physical function $\left(\mathrm{RB}_{\text {fixed }}, 0.55 ; 95 \% \mathrm{CI}, 0.45\right.$ to $0.67 ; p<0.00001)$. The difference was significant across two subgroups, irrespective of concomitant therapy $(p \leq 0.0001)$.

A meta-analysis of the safety of tofacitinib vs. placebo

\section{Risk of serious adverse events}

Data on the incidence of SAEs were available in four studies $[11,13-15]$ on the comparison of tofacitinib with placebo both given concomitantly with MTX and in three studies [16,
17, 20] concerning tofacitinib or placebo given as monotherapy (Fig. 3). There was no significant difference in the frequency of serious AEs between tofacitinib and placebo during 12 weeks of treatment $\left(\mathrm{RR}_{\text {random }}, 0.81\right.$; $95 \% \mathrm{CI}, 0.31$ to $2.14 ; p=0.67$ ). In the subgroup analysis, stratifying RTCs by concomitant exposure to MTX, the differences between the tofacitinib and placebo were not statistically significant either $(p=0.68$ and $p=0.28$, respectively); however, comparing the subgroup results, the concomitant MTX therapy seemed to increase the risk of SAEs in tofacitinib-treated patients.

\section{Treatment discontinuation due to adverse events}

In regard to the risk of withdrawal of patients from therapy due to any adverse events during 12 weeks of treatment, the overall result showed no statistically significant difference between tofacitinib vs. placebo $\left(\mathrm{RR}_{\text {fixed }}, 1.14 ; 95 \% \mathrm{CI}, 0.72\right.$ to $1.80 ; p=0.57)$. However, the results of subgroup analysis 


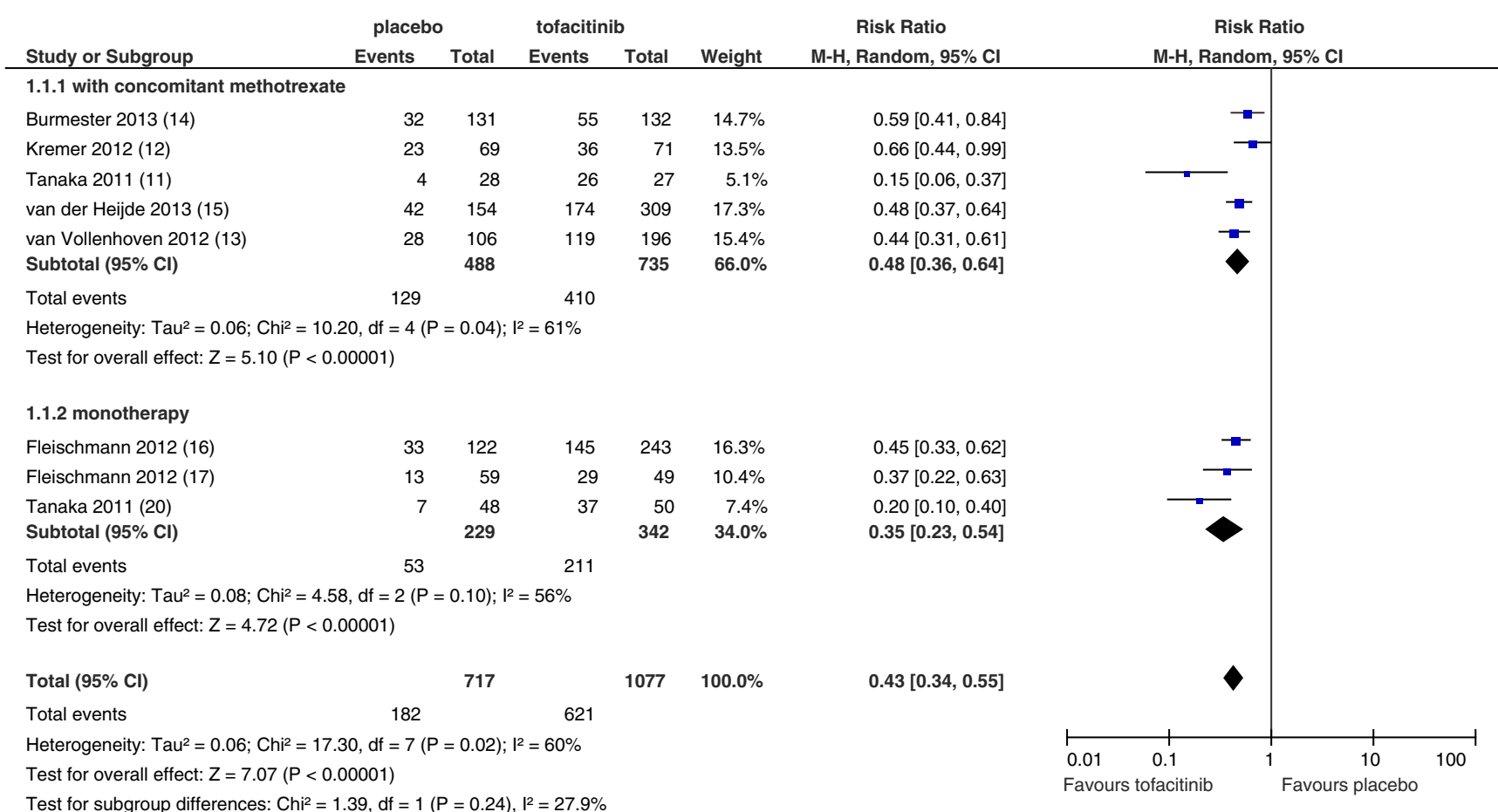

Fig. 2 The effect of tofacitinib compared with placebo on $20 \%$ improvement according to the American College of Rheumatology criteria (ACR20) at week 12

showed slight divergent trends but these findings did not reach statistical significance. Similarly to the risk of SEAs, it seemed that concomitant MTX could increase the risk of treatment discontinuation due to an adverse event; however, it is noteworthy that tofacitinib appears to have an acceptable safety profile.

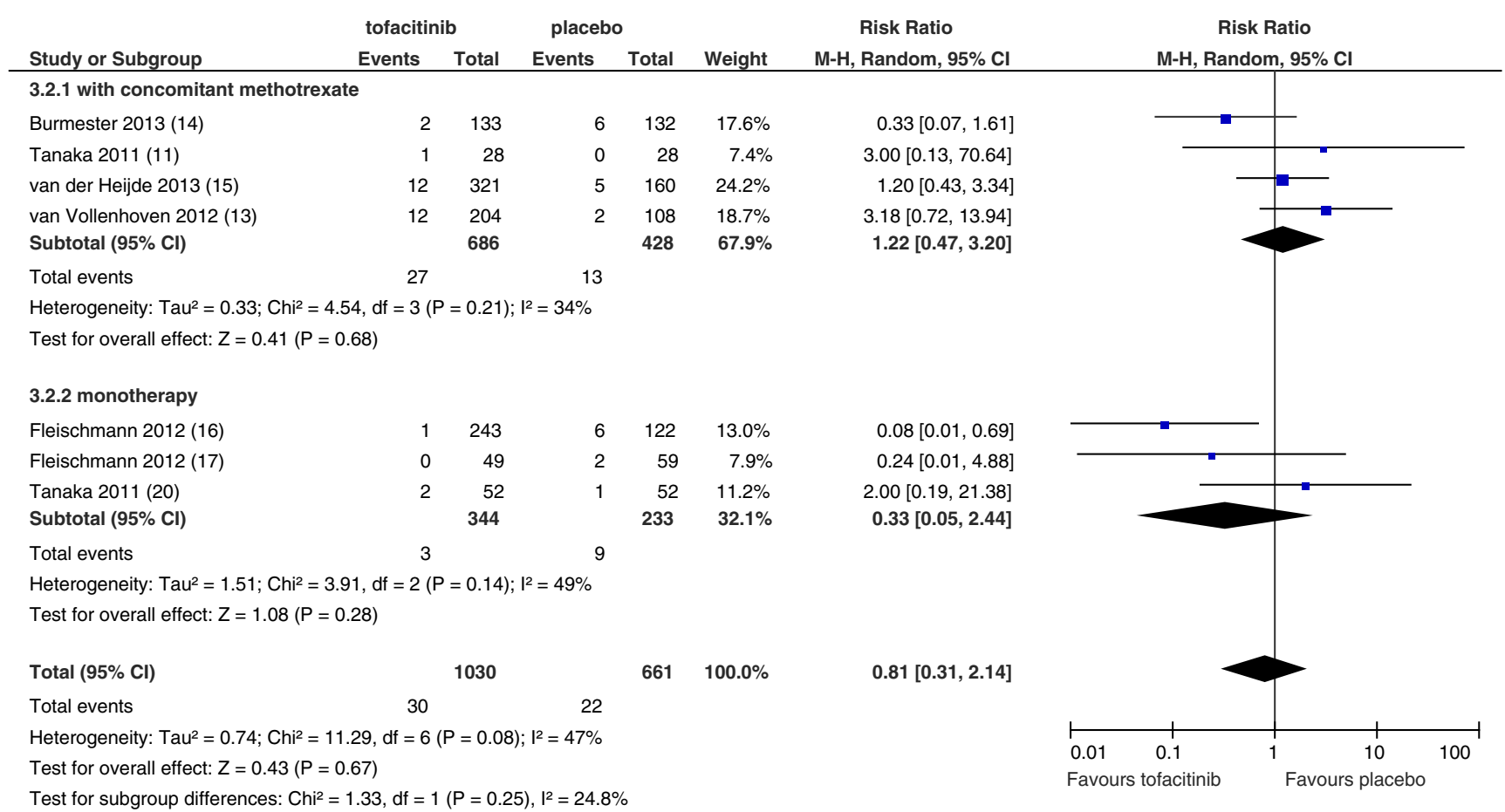

Fig. 3 The effect of tofacitinib compared with placebo on the risk of serious adverse events during 12 weeks of treatment 
A meta-analysis of the efficacy of tofacitinib vs. adalimumab

Data on the efficacy of tofacitinib in comparison with adalimumab (a TNF inhibitor, TNFi) were available only in two placebo-controlled trials [13, 17]. In one study [13], tofacitinib and adalimumab were given concomitantly with MTX, and in the other study [17], the investigated agents were used in monotherapy. Because of the limited number of trials, the included patients were not subdivided according to a background therapy. We compared data on tofacitinib at a dose of $5 \mathrm{mg}$ bid and adalimumab administered subcutaneously at $40 \mathrm{mg}$ once every second week.

\section{$A C R$ response rate}

The relative benefit $\left(\mathrm{RB}_{\text {random }}\right)$ of $20 \%$ improvements according to the ACR treatment response criteria at week 12 was 0.79 (95\% CI, 0.52 to $1.18 ; p=0.25)$ without a significant difference between tofacitinib and adalimumab. Likewise, the ACR70 response rate showed no statistically significant difference between the antirheumatic agents $\left(\mathrm{RB}_{\text {fixed }}, 0.62 ; 95 \% \mathrm{CI}, 0.36\right.$ to $\left.1.07 ; p=0.08\right)$. What is important, based on the ACR50 criterion, is that tofacitinib was found to be significantly superior to adalimumab ( $\mathrm{RB}_{\text {fixed }}, 0.65 ; 95 \% \mathrm{CI}, 0.49$ to $0.87 ; p=0.003$ ). ACR50 responses are presented in Fig. 4 . A total of $34.7 \%$ of the tofacitinib-treated patients achieved a $50 \%$ improvement compared to $22.6 \%$ of patients receiving adalimumab, indicating an absolute benefit of $12.1 \%$.

A meta-analysis of the safety of tofacitinib vs. adalimumab

\section{Risk of serious adverse events and treatment discontinuation due to adverse events}

A meta-analysis on the basis of two RCTs $[13,17]$ revealed no statistically significant difference between tofacitinib and adalimumab in the frequency of SAEs during 12 weeks of treatment $\left(\mathrm{RR}_{\text {fixed }}, 2.00 ; 95 \% \mathrm{CI}, 0.78\right.$ to $\left.5.13 ; p=0.32\right)$. Similarly, the risk of discontinuation of treatment because of adverse events did not differ significantly between the investigated drugs ( $\mathrm{RR}_{\text {fixed }}, 1.17 ; 95 \% \mathrm{CI}, 0.56$ to $\left.2.45 ; p=0.68\right)$.

\section{Discussion}

To our knowledge, this is the first meta-analysis and the most up-to-date systematic review evaluating the efficacy of tofacitinib in RA. What is more is that its methodology followed the methods described in the Cochrane handbook and the meta-analysis was performed according to the PRISMA Statement protocol. The applied search strategy revealed all of the relevant published and unpublished articles. Ten papers reporting on nine RCTs published between 2009 and May 2013 were included in the systematic review, and eight trials were included in the meta-analysis. It should be noted that during study selection, we excluded one openlabel phase I study [22] which investigated the effects of MTX on the pharmacokinetics of tofacitinib in patients with RA.

The results of the meta-analysis are relevant to the population of adult patients with active moderate-to-severe RA who failed on or had an inadequate response or intolerance to MTX, other DMARDs, or TNF inhibitors. Although conventional DMARDs (e.g., methotrexate, leflunomide, sulfasalazine) are generally offered as first-line treatment for the patients with RA, biological DMARDs with usually a TNFi administered as a first choice therapy [4, 23, 24] remain an established treatment option for patients with suboptimal response or intolerance to synthetic DMARDs. A lot of studies have demonstrated the efficacy of the antiTNF therapy in RA [3]. The results of meta-analysis [23] on the basis of seven RCTs comparing the use of infliximab and placebo in RA patients concomitantly using methotrexate showed significantly higher efficacy of infliximab relative to a control in regard to achieving ACR20, ACR50, and ACR70 values during 14-30 weeks of treatment. Aaltonen et al. [24] performed a meta-analysis evaluating the effectiveness of five anti-TNF agents (adalimumab, infliximab, certolizumab, golimumab, and etanercept) compared to either MTX and placebo or placebo alone in the treatment of RA. Their meta-analysis demonstrated that TNFi was more efficacious than placebo but comparable to MTX. Moreover, the combination of TNFi and MTX was found to be superior to either MTX or TNFi alone. TNFi given alone or added to MTX was not associated with an increased risk of serious

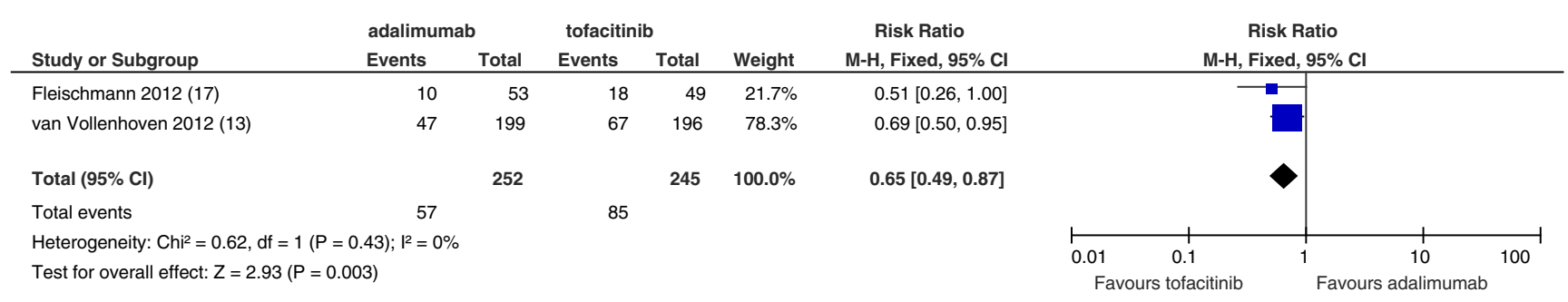

Fig. 4 The effect of tofacitinib compared with adalimumab on $50 \%$ improvement according to the American College of Rheumatology criteria (ACR50) at week 12 
adverse events or any infections when compared with placebo or MTX [24]. Additionally, in the network meta-analysis [25] evaluating the efficacy of EU-licensed biological DMARDs for RA treatment (apart from TNFi, also rituximab or tocilizumab and abatacept), it was shown that all combinations of biological and traditional disease modifiers (except rituximab) were significantly better than conventional DMARDs in improving ACR20/50/70 outcomes in patients with inadequate response to prior MTX monotherapy.

Almost all biological DMARDs approved for the treatment of RA over the past decade require inconvenient, intravenous, or subcutaneous administration associated with specific concerns, including immunogenicity and infusion or injection site reactions; moreover, they are relatively expensive $[3,6]$. Unlike these agents, tofacitinib is an orally administered and easy-to-synthesize small molecule affecting intracellular signal transduction of cytokines involved in the inflammatory process in RA $[5,6]$. In this respect, tofacitinib provides an innovative oral therapeutic option for patients with moderately to severely active RA who failed to respond or were intolerant to traditional DMARDs and/or $\mathrm{TNFi}$, as it targets the multiple pathogenic cytokines and, therefore, may have a broader spectrum of activity than other biological agents, such as TNFi acting against single inflammatory cytokines [3]. However, at the moment, it is crucial to determinate the comparative efficacy of tofacitinib vs. biological DMARDs, particularly TNFi. We provided a direct comparison of tofacitinib and adalimumab on the basis of two RCTs [13, 17], but other head-to-head trials are still lacking. Although these studies were not designed or powered to compare accurately the efficacy of tofacitinib with that of adalimumab, the result of our meta-analysis, indicating the superiority of tofacitinib over adalimumab in respect to ACR50 improvement, might lead to an assumption that the currently tested JAK inhibitor could provide better benefits than the currently used biological DMARDs, like anti-TNF agents.

In the current meta-analysis based on phase II and III studies, tofacitinib administered with MTX background or as monotherapy showed an acceptable safety profile, comparable to placebo and adalimumab in respect to the risk of SAEs and discontinuations due to any adverse events. Concerning safety issues, according to integrated safety data [6], infections, including upper respiratory tract infections and nasopharyngitis, were the most frequent adverse events observed with tofacitinib, and pneumonia and herpes zoster were the most common adverse events leading to discontinuation of treatment. Since all biological agents used in the treatment of RA interfere with the immune system and may cause specific adverse events, which can lead to a discontinuation of treatment [26], JAK inhibitors also were expected to have a higher degree of risk for immunosuppression, and special attention is being paid to the incidence of infections and malignancies [3]. One of the most recent meta-analyses [27] evaluated the safety of RA treatment with various novel protein kinase inhibitors, like JAK, SyK, p38, and c-Kit inhibitors. For JAK inhibitors, the assessment of safety encompassed the same studies that we had included in the current meta-analysis with additional results from phase I study [22]. It was shown that serious infections and malignancies were not significantly more frequent in tofacitinibtreated patients than in placebo groups. On the other hand, it should be emphasized that sensitivity analysis just based on full reports of trials concerning RA with at least 12 weeks of exposure revealed a significantly higher relative risk for hypercholesterolemia in tofacitinib-treated patients compared to placebo [27]. Nonetheless, as stated in the report [6], the overall safety profile of tofacitinib, dosed at either 5 or $10 \mathrm{mg}$ bid, was generally consistent with that observed in patients treated with biological and nonbiological DMARDs.

There are a few limitations to our meta-analysis. The analysis of the efficacy was mainly based on the response rate according to the ACR (20/50/70) criteria. It should be emphasized that this outcome is a composite endpoint, which may be burdened with some limitations, such as unexpected differences in the individual measures of each component. However, despite the fact that we aggregated available data only for HAQ-DI improvement, clinically significant improvements in functional and health status measured by individual components of the ACR response criteria were consistent throughout the studies. Moreover, in all included studies, the response rates were measured according to the ACR criteria that have been defined several years ago [10]. In the revision published in 2007, the American College of Rheumatology suggested that the use of a new hybrid measure of RA response combining the ACR20, the ACR50, and the ACR70 and a continuous score of the mean improvement in core set measures would maximize the sensitivity to change [28]; however, that hybrid measure was not applied in the studies included in the current meta-analysis.

Another important factor is that the efficacy of tofacitinib was assessed only for a dose of $5 \mathrm{mg}$ bid, even though in the included studies various dosages have been evaluated. Based on the results of the tofacitinib development program that investigated its use in the treatment of RA, balancing efficacy and safety data, the FDA approved only the dose of $5 \mathrm{mg}$ twice daily in monotherapy or in combination with MTX or other nonbiological DMARDs. However, it has been confirmed that some patients might benefit from a dose increase to $10 \mathrm{mg}$ twice a day based on clinical response [6].

Though the duration of treatment in the included studies ranged from 6 to 48 weeks, we based the meta-analysis on the data extracted at week 12 . Week 12 was chosen because almost all the studies reported the results for this period, and in some longer lasting trials, patients failing to meet predefined treatment response criteria after 12 weeks of 
therapy were switched from the control group to active drug or from the lower dosages to a higher dose of tofacitinib. The applied method of imputation of the outcomes could introduce a bias to the evaluation of the efficacy results. Although four [12, 14, 16, 17] and two [13, 15] trials lasted up to 24 and 48 weeks, respectively, in part of them, data for efficacy and safety outcomes for periods longer than 12 weeks were not extractable without avoiding imputation analysis. However, we realize that the current meta-analysis would have been powered if the efficacy and especially safety results had been reported at longer time points.

Although the duration of treatment in the studies $[18,19]$ was 6 weeks with an additional 6 -week follow-up period, the reported results were obtained at week 6; therefore, they could not be aggregated with other studies' outcomes extracted at week 12. This study was the first conducted dose-ranging RCT reporting on the efficacy and tolerability of tofacitinib in patients with active RA in whom MTX or TNFi caused an inadequate response or intolerability reactions. Improvement in efficacy outcomes were seen in all groups treated with various doses of tofacitinib. It can be assumed that pooling the results from the studies $[18,19]$ with other results extracted at 12 weeks of treatment would not influence the overall favorable effect of tofacitinib therapy despite the different treatment durations. It is worth to emphasize that the long-term results from 48-week analysis in the study [15] confirm findings seen previously in phase II studies with shorter treatment periods [11, 12].

It should be noted that some publications did not provide enough detailed and extractable data on the outcomes. For this reason, information for some endpoints, mainly concerning ACR50 or ACR70 [11-13, 15], was retrieved as raw data from particular study results provided by the register of clinical trials website. Selective outcome reporting could therefore be a limitation in our metaanalysis. However, we believe that this method would not affect significantly the overall results.

In summary, the results of our meta-analysis have demonstrated that tofacitinib provides a greater efficacy than placebo, showing rapid, statistically significant, and clinically meaningful reductions in signs and symptoms of RA. In addition, so far, tofacitinib seems to present comparable efficacy in relation to adalimumab, but on the basis of one analyzed outcome (ACR50), it can be assumed that this agent has a greater potential to suppress disease activity than TNFi; however, it needs to be confirmed in a larger number of reliable studies. In the light of consistent efficacy across the available RCTs, and manageable as well as predictable adverse effects, the overall risk-benefit ratio of therapy with tofacitinib in RA is favorable. However, there is still a need for long-term post-marketing studies to define the effectiveness of tofacitinib, especially in respect to its safety profile in the real-world population of patients suffering from RA.
It should be noted that tofacitinib is the first-in-class JAK inhibitor approved for RA treatment. Furthermore, tofacitinib has already been investigated in clinical trials for other indications including inflammatory bowel disease, psoriasis, and dry eye syndrome and for the prevention of renal transplant rejection, with promising preliminary results [5].

Conflict of interest The authors disclaim any conflicts of interest pertaining to this article.

Authors contribution All listed authors approved the final version of the manuscript. Conception and design of the review was prepared by P.K and A.M.; P.K., A.M. and N.W. were involved in acquisition, analysis and interpretation of data; P.K. and A.P. provided critical revision and substantive and methodological correction.

Open Access This article is distributed under the terms of the Creative Commons Attribution License which permits any use, distribution, and reproduction in any medium, provided the original author(s) and the source are credited.

\section{References}

1. Tanaka Y, Yamaoka K (2013) JAK inhibitor tofacitinib for treating rheumatoid arthritis: from basic to clinical. Mod Rheumatol 23:415-424

2. Zerbini CA, Lomonte AB (2012) Tofacitinib for the treatment of rheumatoid arthritis. Expert Rev Clin Immunol 8:319-331

3. Bannwarth B, Kostine M, Poursac N (2013) A pharmacokinetic and clinical assessment of tofacitinib for the treatment of rheumatoid arthritis. Expert Opin Drug Metab Toxicol 9:753-761

4. Singh JA, Furst DE, Bharat A et al (2012) 2012 update of the 2008 American College of Rheumatology recommendations for the use of disease-modifying antirheumatic drugs and biologic agents in the treatment of rheumatoid arthritis. Arthritis Care Res (Hoboken) 64:625-639

5. Riese RJ, Krishnaswami S, Kremer J (2010) Inhibition of JAK kinases in patients with rheumatoid arthritis: scientific rationale and clinical outcomes. Best Pract Res Clin Rheumatol 24:513-526

6. Food and Drug Administration (2012) Advisory Committee meeting. Tofacitinib for treatment of rheumatoid arthritis (NDA 203214). http://www.fda.gov/downloads/AdvisoryCommittees/Committees MeetingMaterials/Drugs/ArthritisAdvisoryCommittee/UCM302960. pdf. Accessed 3 May 2013

7. Higgins JPT, Green S (eds) (2011) Cochrane handbook for systematic reviews of interventions version 5.1.0 [updated March 2011]. Cochrane Collaboration, Oxford. www.cochrane-handbook.org. Accessed 3 May 2013

8. Moher D, Liberati A, Tetzlaff J, Altman DG, The PRISMA Group (2009) Preferred Reporting Items for Systematic Reviews and Meta-Analyses: the PRISMA statement. PLoS Med 151:264-9

9. Jadad AR, Moore RA, Carroll D et al (1996) Assessing the quality of reports of randomized clinical trials: is blinding necessary? Control Clin Trials 17:1-12

10. Felson DT, Anderson JJ, Boers M et al (1995) American College of Rheumatology preliminary definition of improvement in rheumatoid arthritis. Arthritis Rheum 38:727-735

11. Tanaka Y, Suzuki M, Nakamura H et al (2011) Phase II study of tofacitinib (CP-690,550) combined with methotrexate in patients with rheumatoid arthritis and an inadequate response to methotrexate. Arthritis Care Res (Hoboken) 63:1150-58. http://www.clinicaltrials. gov/ct2/show/results/NCT00603512. Accessed 3 May 2013 
12. Kremer JM, Cohen S, Wilkinson BE et al (2012) A phase IIb doseranging study of the oral JAK inhibitor tofacitinib (CP-690,550) versus placebo in combination with background methotrexate in patients with active rheumatoid arthritis and an inadequate response to methotrexate alone. Arthritis Rheum 64:970-81. http://clinicaltrials. gov/ct2/show/results/NCT00413660?sect $=$ X9876015. Accessed 3 May 2013

13. van Vollenhoven RF, Fleischmann R, Cohen S et al (2012) Tofacitinib or adalimumab versus placebo in rheumatoid arthritis. N Engl J Med 367:508-19. http://clinicaltrials.gov/ct2/show/results/ NCT00853385. Accessed 3 May 2013

14. Burmester GR, Blanco R, Charles-Schoeman C et al (2013) Tofacitinib (CP-690,550) in combination with methotrexate in patients with active rheumatoid arthritis with an inadequate response to tumour necrosis factor inhibitors: a randomised phase 3 trial. Lancet 381:451-60. http://clinicaltrials.gov/ct2/show/NCT00960440. Accessed 3 May 2013

15. van der Heijde D, Tanaka Y, Fleischmann R et al (2013) Tofacitinib (CP-690,550) in patients with rheumatoid arthritis receiving methotrexate: twelve-month data from a twenty-four-month phase III randomized radiographic study. Arthritis Rheum 65:559-70. http:// clinicaltrials.gov/ct2/show/results/NCT00847613. Accessed 3 May 2013

16. Fleischmann R, Kremer J, Cush J et al (2012) Placebo-controlled trial of tofacitinib monotherapy in rheumatoid arthritis. N Engl J Med 367:495-507. http://clinicaltrials.gov/ct2/show/results/NCT00814307. Accessed 3 May 2013

17. Fleischmann R, Cutolo M, Genovese MC et al (2012) Phase IIb dose-ranging study of the oral JAK inhibitor tofacitinib (CP-690,550) or adalimumab monotherapy versus placebo in patients with active rheumatoid arthritis with an inadequate response to disease-modifying antirheumatic drugs. Arthritis Rheum 64:617-29. http://clinicaltrials.gov/ct2/show/results/NCT00550446. Accessed 3 May 2013

18. Kremer JM, Bloom BJ, Breedveld FC et al (2009) The safety and efficacy of a JAK inhibitor in patients with active rheumatoid arthritis: results of a double-blind, placebo-controlled phase IIa trial of three dosage levels of CP-690,550 versus placebo. Arthritis Rheum 60:1895-1905
19. Coombs JH, Bloom BJ, Breedveld FC et al (2010) Improved pain, physical functioning and health status in patients with rheumatoid arthritis treated with CP-690,550, an orally active Janus kinase (JAK) inhibitor: results from a randomised, double-blind, placebocontrolled trial. Ann Rheum Dis 69:413-416

20. Tanaka Y, Takeuchi T, Yamanaka H et al (2011) Tofacitinib (CP690,550), an oral Janus kinase inhibitor, as monotherapy in Japanese patients with active rheumatoid arthritis: a 12-week phase $2 b$ study [abstract]. Arthritis Rheum 63 Suppl 10:2192

21. Arnett FC, Edworthy SM, Bloch DA et al (1988) The American Rheumatism Association 1987 revised criteria for the classification of rheumatoid arthritis. Arthritis Rheum 31:315-324

22. Cohen S, Zwillich S, Chow V et al (2010) Co-administration of the JAK inhibitor CP-690,550 and methotrexate is well tolerated in patients with rheumatoid arthritis without need for dose adjustment. Br J Clin Pharmacol 69:143-151

23. Wiens A, Correr CJ, Venson R et al (2009) A meta-analysis of the efficacy and safety of using infliximab for the treatment of rheumatoid arthritis. Clin Rheumatol 28:1365-1373

24. Aaltonen KJ, Virkki LM, Malmivaara A et al (2012) Systematic review and meta-analysis of the efficacy and safety of existing TNF blocking agents in treatment of rheumatoid arthritis. PLoS One 7:e30275

25. Orme ME, MacGilchrist KS, Mitchell S et al (2012) Systematic review and network meta-analysis of combination and monotherapy treatments in disease-modifying antirheumatic drug-experienced patients with rheumatoid arthritis: analysis of American College of Rheumatology criteria scores 20, 50, and 70. Biologics 6:429-464

26. Yang CT, Kuo CF, Luo SF, Yu KH (2012) Discontinuation of antiTNF- $\alpha$ therapy in a Chinese cohort of patients with rheumatoid arthritis. Clin Rheumatol 31:1549-1557

27. Salgado E, Maneiro JR, Carmona L, Gomez-Reino JJ (2013) Safety profile of protein kinase inhibitors in rheumatoid arthritis: systematic review and meta-analysis. Ann Rheum Dis. doi:10.1136/ annrheumdis-2012-203116

28. American College of Rheumatology Committee to Reevaluate Improvement Criteria (2007) A proposed revision to the ACR20: the hybrid measure of American College of Rheumatology response. Arthritis Rheum 57:193-202 